\title{
Benchmarking for fisheries governance
}

\author{
R. Quentin Grafton ${ }^{\mathrm{a}, *}$, Tom Kompas ${ }^{\mathrm{a}, \mathrm{b}}$, Richard McLoughlin ${ }^{\mathrm{c}}$, Nick Rayns ${ }^{\mathrm{c}}$ \\ ${ }^{a}$ Crawford School of Economics and Government, The Australian National University, J. G. Crawford Building (13), Ellery Crescent, \\ Canberra ACT 0200, Australia \\ ${ }^{\mathrm{b}}$ Australian Bureau of Agricultural and Resource Economics, Australia \\ ${ }^{\mathrm{c}}$ Australian Fisheries Management Authority, Australia
}

Received 18 November 2006; accepted 9 December 2006

\begin{abstract}
The paper develops a benchmarking framework to improve fisheries governance and promote resilient ecosystems and profitable fisheries. The benchmarking includes five key components: accountability, transparency, incentives, risk assessment and management; and adaptability. Collectively, these factors provide a framework to benchmark and improve fisheries governance. Initial findings from benchmarking in two of Australia's Commonwealth fisheries indicate that the framework provides an important tool to help overcome the underlying causes of unsustainability in capture fisheries-poor and/or ineffective fisheries governance.
\end{abstract}

(C) 2007 Elsevier Ltd. All rights reserved.

Keywords: Fisheries; Governance; Sustainability

\section{Introduction}

Fisheries governance involves two key challenges. The first is the need to understand the current state of the world, and especially the principal feedbacks of fisher and ecosystem dynamics. The second is the necessity to translate this knowledge into effective governance to achieve biological, social and economic goals. Using diverse experiences in fisheries management, we provide a framework to benchmark fisheries governance to improve performance and promote resilient ecosystems and profitable fisheries.

To explain why benchmarking is required, we first review the pitfalls and opportunities of current management paradigms and their implications for how fisheries are currently governed. Section 3 of the paper develops a benchmark framework as a synthesis of existing management approaches. The framework is built around five key governance concepts: accountability, transparency, incentives, risk assessment and management, and adaptability.

\footnotetext{
${ }^{*}$ Corresponding author. Tel.: + 61261256558 ; fax: + 61261255570 .

E-mail address: quentin.grafton@anu.edu.au (R. Quentin Grafton).
}

Section 4 explores how the benchmarking is being developed and applied in Australia's Commonwealth fisheries. We conclude with the prospects for benchmarking to improve fisheries governance and resolve the on-going challenges of the conduct of fisheries in the marine environment.

\section{Fisheries governance: pitfalls and opportunities}

Before presenting the benchmarking framework we review the pitfalls and opportunities of approaches currently offered as 'fixes' to the decline of marine ecosystems. We first describe what the precautionary principle can and cannot deliver to managers, and use this to discuss the implications of reference points and target reference points in fisheries management. We also examine the failures of not connecting targets to instruments, and explain why incentives-based approaches alone cannot resolve the challenges that hinder effective fisheries governance. We conclude the section with a review of the ecosystem approach to fisheries (EAF), previously known as ecosystem-based fisheries management. 


\subsection{Precautionary principle}

The risks associated with fisheries management come in two main forms - one, uncertainty over the current status of fish stocks and the marine environment and two, uncertainty over the underlying dynamics, feedbacks and factors (natural and anthropogenic) that determine future stock levels. To avoid making risky decisions in the face of uncertainty many managers in the past 10-15 years have attempted to adopt the 'precautionary principle' that was contained in the Rio Declaration of the 1992 Earth Summit. The principle is a 'duty of care' that recognizes that uncertainty over the effects of management actions should not be used as an excuse to preclude costeffective measures to prevent environmental degradation [1]. The principle is widely accepted and, for example, is enshrined in FAO technical guidelines for responsible fisheries [2].

In practice, the precautionary principle has been what implemented through the establishment of biological target and limit reference points [3] that are occasionally associated with harvest control rules. A difficulty with this approach is that managers will never know with certainty, and at what point in time, what the limit reference point is and beyond which there should be no harvesting. Thus, although low fish stocks are, in general, associated with more risky outcomes that include a higher probability of unforseen collapses [4], longer recovery times from collapses and undesirable ecosystem shifts, it is difficult to know with certainty the extra risk from not reducing the harvest by a marginal amount. Limit reference points also change with environmental conditions, and whether a limit or threshold has been crossed can almost never be known with absolute certainty until a stock actually collapses. This is exacerbated by the often considerable time frames involved in stock assessments; catches in one fishing season are often assessed the following season for application of management controls in the subsequent season.

The consequence of unresolved uncertainties is that despite scientific recommendations to reduce harvests in line with fishing mortality consistent with precautionary reference points, the European Commission has implemented higher harvests in 31 out of 35 stocks and sub-stocks than recommended by the Advisory Committee on Fisheries Management (ACFM) of ICES [5]. This astounding pattern of total allowable catches (TACs), set at a level higher than that advised by scientists, also occurred in $1980 \mathrm{~s}$ and 1990s [6] prior to the implementation of precautionary limits. In some cases, the TAC has been several times larger than that advised by the ACFM. For instance, in 2002 ICES recommended a harvest moratorium for North Sea cod, but the Council of Ministers of the European Union only implemented a $45 \%$ reduction, coupled with additional effort restrictions [7]. A similar story of implementing higher TACs than recommended exists for other large demersal fisheries in the North Atlantic [8] and in Australia [9]. The key point is that without structural change in how fisheries are governed the precautionary principle, by itself, will fail to prevent riskprone decisions.

\subsection{Reference points, rules and discretion}

The failure to effectively implement precautionary limits has led many fishery scientists, and some managers, to call for a 'rules versus discretion' approach to the setting of TACs. In the rules-based approach total harvests or levels of escapement are always set to ensure there is only a very low risk that the stock will collapse. This rules-based approach is precautionary and avoids decisions that impose the highest ecological risk on the fishery, or what has been called acute unsustainability [10].

The application of limit or precautionary reference points gives supremacy to ecological sustainability. This approach, however, may result in unnecessary caution as the cost for avoiding risky outcomes because reference points are applied within confidence limits, and without complete certainty as to what might happen. Limit reference points also pose difficulties in fisheries where harvesters have a limited ability to target species, and where they catch a substantial amount of non-target species that have a high mortality rate when discarded. In such cases, it is possible that a lucrative fishery might be closed to ensure a non-target species does not fall below its limit reference point [11].

Despite the appearance, a fixed decision or control rule in relation to precautionary reference points does not remove discretion from fisheries management. For instance, the actual decision rule and the reference point itself depend on the type of fishery, the data available and the models used, all of which depend on the judgements of fisheries scientists and managers. Reference points are often based on harvest levels or stocks, but could also be determined as a fraction of natural mortality [12], spatial indicators [13] or, size-based indicators [14], as no single reference point is sufficient to measure the state of marine ecosystems [15]. The use of single-species reference points may also miss important interactions that should be accounted for, such as trophic dynamics and species diversity [16].

If stock assessment models are used to generate precautionary reference points then they will need to be continually updated, which involves a myriad of decisions about model assumptions and the data to use. If the precautionary reference point is based on data and levels of absolute abundance then a great deal of discretion is required as to what data, such as catch rates at particular locations and times, and at what point trends in the data indicate the precautionary reference is reached [17]. This is especially true if precautionary reference points are based on the pre-fished biomass (B0) where important ecosystem fluctuations are independent of fishing mortality [18]. The key point is that although precautionary reference points are essential in avoiding risk-prone outcomes, qualitative 
judgements and discretion are still required elements for effective fisheries management.

\subsection{Target reference points}

Rules for setting harvest levels have been proposed to ensure the biomass does not fall below a target level, such as that associated with the maximum sustained yield (MSY). This is also a rules-based approach to setting TACs; however, in this case it is not applied to prevent a risk-prone decision but rather to achieve a particular goal of fisheries management, such as maximizing the sustainable level of harvest from a given stock of fish.

The added problem with rules in the case of target reference points is that it gives supremacy to a particular biomass or ecosystem target without due consideration of social and economic costs and benefits from achieving this goal. For instance, a policy that imposes a harvesting moratorium to rebuild a fishery from some point below MSY biomass ( $B_{\mathrm{MSY}}$ ) may be undesirable if the social and economic costs of a zero harvest are very high. The $B_{\mathrm{MSY}}$ target may also be problematic because in many fisheries a stock size greater than this would maximize the sustainable returns from fishing [19] - the biomass that maximizes the economic yield $\left(B_{\mathrm{MEY}}\right)$. In the case of stock rebuilding strategies to a $B_{\mathrm{MSY}}$ or $B_{\mathrm{MEY}}$ target, discretion is also required in determining the trade-offs and the speed of transition-an adjustment that cannot be dictated by a one-size-fits-all decision rule or a uniform target for all fisheries.

By contrast to precautionary reference points, a rulebased approach to achieve a target reference point may also raise monitoring and enforcement costs. For example, if TACs are set simply to achieve a disputed target biomass then fishers who consider such an approach as unnecessarily conservative may reduce compliance with fishery management regulations. In turn, this requires a more effective system of monitoring to avoid increased misreporting of landings, bycatch and discards that could affect the reliability of the stock assessment process. The point is that the setting of TACs requires discretion and judgements and should involve a process that actively involves fishers and other stakeholders [20], although not at the expense of ecosystem sustainability.

\subsection{Targets versus instruments}

Quantifiable targets whether they are in terms of reference points, or other forms, provide the means by which management actions can be evaluated and improved upon. Despite the problems with some goals, such as MSY [21], and also conflicts between objectives [22], we contend that many of the failures of fisheries management have arisen not from inherent problems in targets, but from ineffective instruments to achieve them.

The rebuilding of fish stocks illustrates why targets must always be fully integrated with instruments. For example, where fishers have no long-term property right or assurance that they will be the beneficiaries of future gains from short-run reductions in harvests, they will almost always oppose TAC reductions designed to reach biomass targets. Such opposition to TAC reductions has arisen in the New England groundfish fisheries [23], and elsewhere. ${ }^{1}$ By contrast, where fishers have well recognized and durable harvesting rights they have, in several instances (New Zealand's east rock lobster fishery, Canadian sablefish fishery, Tasmanian abalone, Iceland herring fisheries) taken the lead in arguing for lower TACs and more sustainable fishing practices [25].

The appropriate strategic instrument must also be implemented in an effective way tactically otherwise the target will not be achieved. For instance, the introduction of a marine reserve of an inappropriate size and in the wrong location may be detrimental to conservation goals if fishers were to redirect effort from a population sink to a source. To be effective, instruments also need suitable targets. For example, individual and tradeable harvesting rights will do little to engender sustainable practices if the TAC is set at a level above which the industry can profitably harvest. This is because if the TAC is a nonbinding constraint, the property right will not provide the appropriate price signals to fully promote sustainable fishing practices.

\subsection{Incentives}

To prevent overfishing many managers have tried to coerce fishers to behave in ways that are contrary to their personal interests. This has involved a range of controls, primarily on the inputs employed by fishers, such as vessel size, gear restrictions, season length, etc. in an attempt to keep fishing mortality at a desired level. In many cases the 'command and control' approach has been unsuccessful because fishers have been able to substitute from regulated to unregulated inputs in what has been called 'effort creep'. In this game, managers are forced to apply ever more stringent controls over a wider range of inputs [19], sometimes termed an 'input control spiral'. In turn, this makes enforcement more difficult [26] while making it more costly to fish.

The alternative is to manage in ways that fishers' interests become closer aligned to societal objectives, such as sustainability. This requires that fishers have a stake in the future health of fishery resources such that they will suffer the costs of overexploitation, but can also reap the gains of sustainable practices. For instance, the aligning of private and social interests can be promoted if fishers have, at an individual or community level, exclusive, durable and well-defined harvesting or territorial rights to fishery resources. This requires a delineation of jurisdictional,

\footnotetext{
${ }^{1}$ See Box 2.1 of Walters and Martell [24, p. 29] where they provide a long quotation attributed to Hilborn as to why fishermen oppose stockrebuilding plans, and what can be done to obtain their support.
} 
legal and governance boundaries consistent with ecological boundaries that avoid spatial mismatches [27].

Implementing the appropriate incentives and property rights within fisheries is not without its difficulties [28], but it has led to improved outcomes in various fisheries around the world [29,30]. Ensuring fishers have well-developed property rights may even be a necessary condition for successful fisheries management [23]. The key insight is that incentive-based approaches, along with effective governance and oversight, promote sustainable fishery outcomes [25].

\subsection{Ecosystem approach to fisheries (EAF)}

In response to shortcomings of existing commercial and target-species oriented fisheries management [31], scientists and managers have developed an alternative vision to managing marine ecosystems under uncertainty - the EAF. The approach incorporates many of the 'best practice' aspects of existing fisheries management and is implemented via strategies that attempt to balance, given uncertainties, diverse objectives within ecologically boundaries [32]. It is consistent with the Food and Agricultural Organization (FAO) code of conduct for responsible fisheries (CCRF) adopted in 1995 that imposes an obligation on all states and resource users to conserve ecosystems, ensure the conservation of living marine resources, and apply the precautionary principle to fisheries management to achieve resilience [33].

A key aspect of EAF is the use of spatial management tools, frequently implemented via marine protected areas (MPAs), designed to meet biodiversity and habitat objectives deemed necessary for healthy ecosystems. Although spatial management has long been a tool of fisheries management in terms of area closures, they have primarily been used to provide regulatory control for target species. By contrast, EAF gives a much greater role to spatial management - to sustain the productive capacity of marine ecosystems rather than simply achieve management goals for target species. EAF also emphasizes the importance of managing uncertainty via the precautionary principle.

The difficulty with EAF is in translating the approach into feasible tactics at the management level. EAF is also a difficult concept to grasp for some stakeholders, especially the use of probabilities of events and the management of uncertainties inherent in the approach. The various components of EAF, if effectively accounted for by managers, also makes decision-making a much more complex exercise than so-called target species management [34]. ${ }^{2}$ Moreover, overlaying even more contentious ecosystem goals into an often difficult decision-making process between fishers and managers will not avoid the on-going dilemma of what happens when uncertain science collides with social and economic interests [35].

\footnotetext{
${ }^{2}$ See Fig. 1 of Garcia et al. [32, p. 9] for an illustration of the many components and interactions inherent in EAF.
}

Stakeholders are, rightly so, viewed as integral to EAF. Actively involving fishers in decision-making has been variously described as a 'bottom up' approach to fisheries management and may include co-management approaches [36]. However, a substantial devolution of management authority to fishers may be counter productive in the absence of appropriate incentives. The next and crucial step to achieve the aims of EAF must be to develop ways to overcome the 'missing link' in fisheries - how to effectively manage uncertainty and connect higher-levels goals, such as ecologically sustainable development (ESD), to day-today management decisions.

\section{Benchmarking for fisheries governance}

We develop a synthesized approach to fisheries governance and a framework for benchmarking performance that provide a set of practical governance steps to implement the CCRF and EAF in tactical management decisionmaking. Our approach encompasses the notions of ecosystem, socio-economic, community and institutional sustainability [37] and focuses on the actions of all stakeholders, not just managers, to achieve persistence of desired states of the world, and resilience to speedily return to these states following disturbances or shocks. ${ }^{3}$ The approach integrates aspects of various paradigms such as the precautionary approach $[1,2]$, adaptive management [40], integrated ocean management [41], incentives-based approaches [25,42], systems approaches [43], 'bottom-up' management [44], co-management [45], risk analysis [46] and robust management [37], among others.

Our benchmarking focuses on addressing the fundamental cause of poor marine ecosystem outcomesineffective and inappropriate fisheries governance. It is based on three key premises. First, the overriding goal for fisheries managers is to ensure resilient marine ecosystems and sustainable fish stocks on which commercial and recreational fishers depend. This requires high-order objectives enshrined in legislation, acted upon through various strategies, and cost-effective tactics such as the use of precautionary reference points. Second, managers must explicitly account for uncertainty over the current and future state of marine environment, and the effects of management actions. This requires risk assessment that includes analysis of alternative management actions, and risk management that uses mixed strategies to cope with multiple uncertainties. Third, resilient marine ecosystems and sustainable fisheries and profitable fisheries are complements that are mutually reinforcing. This demands incentive-based approaches at both the fisher and manager level to ensure that individual interests coincide, as much as possible, with societal interest so as to discourage

\footnotetext{
${ }^{3}$ We combine the Holling [38] and Pimm [39] notions of resilience because it is not only the ability to return to a desired state, but the speed of this response, that matter for fisheries management.
} 
unsustainable fishing practices and to overcome agency failures.

Benchmarking for improved governance recognizes that management actions should differ across fisheries depending on the current state, history, level of exploitation, institutional capacity, etc. However, it identifies critical aspects of governance to improve fisheries outcomes that include, but are not limited to accountability, authority and responsibility, transparency, incentives, risk assessment and management, and adaptability. These governance factors can be used to benchmark and improve fisheries management performance. In Section 4 we explore how this benchmarking is being developed in the context of the Australian Commonwealth fisheries, but we first present an overview of the five factors.

\subsection{Accountability, authority and responsibility}

Individuals need to be accountable for their decisions and actions in a meaningful way so that mistakes and errors can be identified and remedied as necessary. This requires performance indicators at various levels: ecosystem, fish stocks, and economics so as to identify the effects of management actions [47]. It also demands that someone must be accountable for management decisions. This is not an argument against consultative processes that can improve the quality of decisions and the information set available to managers, but rather that such advice supports rather than replaces accountable individuals in the decision making process.

In hierarchical management structures accountability for decisions may be high up the 'chain of command' and can even reside in the hands of a Minister of Fisheries, or equivalent. Ideally, operational accountability should be placed at the management level rather than at the political level, and with the people most qualified to make the decisions. By contrast, politicians should be held accountable for ensuring adequate funding, the overall governance structure and the acceptable risk boundaries (ecological and economic) to be implemented by managers. This latter point is critical - it is elected officials who must articulate the community and societal interest in the management of risk to fish stocks and their supporting environments. This allows managers to focus on management tools and plans to meet objectives, making the management process more effective.

A 'bottom up' and managerial approach to decision making requires that those who are accountable and responsible also have the appropriate authority to make decisions. In other words, it makes little sense to make a fishery manager accountable for decisions that are made further up the chain of command. Unless accountability and authority are combined then the management system faces the danger of 'passing the buck'. The key point is that an effective governance structure requires individuals to be accountable for decisions and actions, and those people with the responsibility must be given the authority to make the decisions.

\subsection{Transparency}

In any governance structure access to relevant and timely information is critical to good decision-making. This requires transparency at various levels - the information supplied to decision makers, the reasons and justification for the decisions made, and assessments and evaluations as to the outcomes associated with past decisions. Without full transparency decision makers may not be held accountable for their actions (internally and externally), and there cannot be an effective quality feedback loop to ensure past mistakes are identified, studied and corrected. Full transparency also promotes greater acceptance of the outcome of decision making even from those that may be made worse off - an important attribute when fishery managers wish to implement stock rebuilding or change harvest allocations among fishers.

\subsection{Incentives}

A huge literature exists on the effects of incentives. A finding common to many thousands of studies at different places and times is that self-interest is an important (but not the sole) motivator of human behavior. Thus governance systems that align the self-interest of individuals with that of a community or society are generally much more effective than methods of coercion at achieving welfare goals $[48,49]$. For example, to prevent overexploitation of fish stocks controls are often placed on the season length to avoid too many fish being caught. This control, however, in the absence of well-defined property rights creates a dynamic whereby fishers have an even greater incentive to invest in extra gear and equipment to be able to harvest the same amount of fish as they did previously, but in a shorter time period. As a result overcapacity increases, average profits decline and fisheries become more vulnerable to unexpected economic and environmental shocks [50].

The incentive approach to fisheries is most closely identified with the use of individual harvesting rights, but it includes territorial user rights and community rights [23]. Incentives can also be used to promote broader ecosystem goals such as with the use of dolphin mortality limits in the Eastern Tropical Pacific that have dramatically reduced dolphin by-catch associated with the harvesting of yellowfin tuna [51]. The use of incentives can also be applied to reduce habitat damage [52] by fishers, and to generate funds for the conservation of endangered species.

\subsection{Risk assessment and management}

A difficulty in fisheries governance is the inability to know with certainty the present and future states of the world. This arises because of difficulties in identifying initial overexploitation, the level of fishing mortality, and the causes of fluctuations in populations [53]. In turn, this 
makes predictions about future states of the world highly unreliable.

Uncertainties require managers to consider, how, when and where fish are caught [54]. In turn, this demands mixed strategies that provide different options in alternative states of the world [55]. For instance, even with optimal harvesting a 'no take' area can generate a resilience effect that allows for quicker recovery and also spillovers to harvested areas following a negative shock [56]. The key insight is that confronting uncertainty demands an appreciation that a complete reliance on any single instrument, be it TACs or reserves, may fail to ensure a viable population in the long run in the presence of multiple uncertainties.

Critical to the success of managing the unexpected is risk assessment that evaluates possible outcomes and the likely consequences of management decisions [46]. This should involve the modeling of ecosystem constraints and unpredictability, and assessments of which trajectories ensure persistent and resilient ecosystems and also sustainable target fish populations. This approach to confronting uncertainties has been called management strategy evaluation (MSE). It involves a strategy or planned course of action, a specification of computer models of the system, and scenarios and simulations of alternative states of the world in terms of target species $[57,58]$.

\subsection{Adaptability}

Under uncertainty management actions must, of necessity, be responsive or flexible to unexpected events. Active adaptive management takes this much further and requires that managers consider alternatives about how states of the world evolve, experiment where appropriate to learn additional information that can improve decision making, and simulate and compare the effects of different policies under various scenarios [59]. Its principal benefit is that it provides a systematic framework for assessment of alternatives to improve upon existing practice while also explicitly considering uncertainties. This approach does not control the uncertainties faced by managers, but should allow for a quicker and better-informed responses to unexpected shocks.

Adaptability also refers to flexibility of institutional structures to adjust to, and to cope with, change. This can occur at the tactical level with in-season adjustments of TACs based on updated information or analysis at a higher operational level in terms of overall fisheries governance. It also includes the capacity to respond to change that can arise from 'nested' management structures [60]. For instance, local fishing communities can exercise a degree of control over fishers that can supplement monitoring, often at lower cost, than that available from state authorities [61]. Fishers themselves can also improve governance through the transfer of traditional knowledge [62] provided there is sufficient social capital to 'lubricate' the exchange [63], and the information can be utilized and translated into improved management actions.

\section{Benchmarking the Australian Commonwealth fisheries}

To illustrate how benchmarking might be applied, we evaluate the performance of two of Australia's Commonwealth fisheries. We emphasize that the extent to which the five governance factors can be used to improve fisheries governance is largely independent of the capacity of management authorities. For instance, in poor countries with few resources the ability to undertake risk assessment may appear limited, but the framework provides a guide to the causes of unsustainability and how they might be overcome even with very limited data.

\subsection{Background}

Australia's fisheries stretch from the subantarctic to the tropics and cover a huge range of habitats. Jurisdiction in the offshore fisheries is vested in the Australian federal government while Australia's State governments and the Northern Territory are charged with managing mainly their inshore commercial fisheries, and also recreational fisheries. The Australian Government managed fisheries are designated Commonwealth fisheries, and since 1992 their management responsibility has been assigned to a statutory authority, the Australian Fisheries Management Authority (AFMA).

Under its original legislative requirements, AFMA is required to implement efficient and cost-effective management, promote ESD and maximize economic efficiency. A significant proportion of its operations are funded through levies on the fishing industry and the Australian Government partially pays for research and compliance. The authority for management is vested in AFMA's Board of Directors - a body that is largely expert-based and includes fishing industry members. The Board receives advice from management advisory committees (MACs) and resource assessment groups (RAGs). MACs and RAGs are stakeholder based involving managers, industry, scientists and conservation NGOs under an independent Chairperson.

AFMA has undertaken active stakeholder input and the Australian Government has provided substantial funding on fisheries research and buybacks of fishing effort. Despite these initiatives, in 2004 the Australian government's Bureau of Rural Sciences (BRS) judged that 17 species in the 23 fisheries under AFMA management were overfished such that the stock levels were beneath $\mathrm{B}_{\mathrm{MSY}}$ targets [64]. AFMA's pursuit of maximizing economic efficiency has also been less than successful and has been hampered by definitional issues over what should be maximized and a number of legal challenges. Declines in fishery efficiency [50], industry overcapacity and substantial increases in fuel prices since 2004 have led a crisis in profitability for many fishers [64].

A review of the shortcomings of current fisheries management was conducted in 2002/2003 that resulted in numerous recommendations, but in effect provided no new policy guidance or shifts in policy settings. After extensive 
discussions about why stocks trends continued to be negative and overall industry profitability similarly trended downward, the Minister of Fisheries announced in 2005 a structural adjustment package worth A $\$ 220$ million, and also provided AFMA with a 'Ministerial Direction'. The Direction is a statutory instrument with which AFMA must comply. Importantly, it specifies the community level interest, via an explicit government decision of the risk boundaries, within which AFMA must make its management decisions. Although the application of this Direction is in the early stages, it is having a beneficial effect in making the debate more constructive as to how to restore overfished stocks and improve economic performance. This current dialogue makes it clear why AFMA, in the absence of any explicit policy guidance from government about its expectations for fisheries management, struggled to successfully pursue its ESD and economic efficiency objectives.

A key provision of the Direction is that AFMA follow a Harvest Strategy Policy (HSP) consistent with world best practice that puts an end to overfishing and rebuilds fish stocks. In addition, a default ' $20 / 40$ ' harvesting strategy is to be instituted whereby target fishing ceases at $20 \%$ of B0 and reductions in harvest are required whenever current breeding biomass is assessed to be below $40 \%$ of $\mathrm{B} 0 .^{4}$ Another key aspect of the Direction is that ITQs be introduced into all Commonwealth fisheries by 2010, unless a strong case can be made on a fishery-by-fishery basis that to do so would be detrimental or not cost effective. The success, or otherwise, of AFMA to implement this Direction will be judged by independent advice on the status of fish stocks and the profitability of the fishing industry.

Further strategies are presented to address the gaps in fisheries governance in Australia's Commonwealth fisheries. These strategies are presented under the subheadings: enhanced reporting system (ERS), ecological risk assessment (ERA), ecological risk management (ERM), and transparent management plans (MPs).

\subsection{Enhanced reporting system (ERS)}

A key issue for Australian Commonwealth fisheries is to develop a reporting system that includes independent assessment of the status of marine ecosystems in defined marine bioregions that relate, as much as possible, ecosystem outcomes to fisheries management actions. This would complement existing reports on stock status and, for selected fisheries, economic status. Any report would, however, need to be interpreted because changes could arise from external factors independent of fisheries governance. For instance, declines in ecosystem may arise

\footnotetext{
${ }^{4}$ For some fish species $B_{\text {MSY }}$ may, in fact, lie between $20 \%$ and $40 \%$ of B0 [65]. In such cases stock rebuilding may not be necessary for ecological sustainability reasons although it might be justified for economic efficiency depending on the value of $B_{\mathrm{MEY}}$.
}

from an oil spill or climate change, reductions in fish stocks might occur from oceanographic events, and falls in profitability could arise from market conditions all of which are independent of AFMA management actions.

Fishery performance reports could be used to determine the trend over time in ecological, stock and economic indicators and whether management promotes resilience. However, the success of the reporting process would depend on the development of appropriate performance indicators $[47,66]$. The choice of indicators to use should be dictated by the user, the amount and quality of information available on a fishery and bioregion basis, and also the costs of using the information relative to the benefits of management. These indicators would also need to connect to the higher-level goals of management - ensure sustainability and to maximize the net economic returns from management to the Australian community.

\subsection{Ecological risk assessment (ERA)}

The Ministerial Direction to AFMA and the draft HSP offer a significant step forward in defining the risk boundaries that will allow fisheries managers to do their job more effectively. The default ' $20 / 40$ ' harvest strategy policy settings specify a non-negotiable boundary in terms of allowable fishing mortality that is consistent with the precautionary principle. ERA offers a wider view of risk when dealing with the marine ecosystem and the impact of fisheries on it. In particular, it provides an approach to determine levels of risk and direct management towards reducing high risk elements.

\subsection{Ecological risk management (ERM)}

ERA requires a management response that includes spatial, catch and gear controls. Approaches could include real-time monitoring that can help managers signal declines sooner, which reduces risk. However, ERM can be costly and, thus, managers and fishers face a trade-off between management costs and fishery access. In other words, effective ERM reduces management risk that should allow for larger TACs or longer fishing seasons, all else equal. Provided the stock is assessed at or around the target reference point, that is, it is at an acceptable level of risk, there should be more choice for industry in terms of shortterm catch levels and perhaps more devolved decision making to MACs.

\subsection{Management plans (MPs)}

Critical to achieving management goals are well-defined strategies and tactics that are evaluated, and if necessary updated, on a regular basis. An improvement over current practice at AFMA would be to make all MPs much more transparent, dynamic and adaptive to species, ecological and economic change. MPs would need to be part of a broader system of integrated oceans management [41] and 
would help satisfy one of the key principles of the Marine Stewardship Council (MSC) - management effectiveness. ${ }^{5}$

A key aspect of MPs in fisheries that require rebuilding is the harvest level and speed of adjustment to reach $B_{\mathrm{MEY}}-$ a target that will vary according to current fleet structure, information on the stock status and other factors. If above a precautionary limit, the level of fishing mortality should be set to enable rebuilding to a target at a rate that takes into account species longevity and fecundity, stakeholder input, and also maximizes net economic returns. In a rebuilding phase, the judgement of management performance should not be on the speed of adjustment, but rather the direction of change (towards or away from the target) as a lower harvest strategy does not always generate a higher economic payoff.

To illustrate how gaps in governance can be identified and improved we evaluate two AFMA managed fisheries - the Northern Prawn Fishery (NPF) and the Southern and Eastern Scalefish and Shark Fishery (SESSF).

\subsection{Northern Prawn Fishery (NPF) and the Southern and Eastern Scalefish and Shark Fishery (SESSF)}

Our benchmarking framework is best applied on a fishery-by-fishery basis. The results, however, can be used to provide an overall evaluation of fisheries governance. To illustrate how the framework can be applied, Table 1 which is developed by the authors presents the five governance factors and their subcomponents in relation to two Commonwealth fisheries: the NPF and the SESSF.

The NPF is described in detail in Kompas et al. [50] and is managed primarily by season closures and input controls on the size of gear that can be used and limits on the number of statutory fishing rights. The principal harvested species are grooved tiger, brown tiger, white banana, and red-legged banana prawns. Stocks are strongly influenced by weather patterns, generally peaking in years in which there has been high rainfall. The variability of stocks makes it difficult to set catch or effort in a way that protects spawning stocks, but also allows operators to profit from a year in which prawns are abundant.

A description of the SESSF is provided in Fox et al. [68]. The SESSF is a multi-species and multi-gear fishery stretching from southern Queensland, around the New South Wales, Victorian, Tasmanian coastlines to Albany in Western Australia. The bulk of the catch consists of twenty species or species groups, managed by individual transferable quotas, but around a hundred species of finfish and deepwater crustaceans are commercially caught. The two fisheries are Australia's most valuable with the NPF

\footnotetext{
${ }^{5}$ The three MSC principles are (1) the condition of the fish stocks, (2) the impact of the fishery on the marine environment and (3) the fishery management systems. The third principle evaluates management effectiveness to ensure a sustainable fishery and to minimize the impact of fishing on the marine environment [67].
}

Table 1

Benchmarking for Fisheries Governance in Australia's Northern Prawn Fishery (NPF) and South and Eastern Scalefish and Shark Fishery (SESSF) in 2006

\begin{tabular}{|c|c|c|}
\hline & NPF & SESSF \\
\hline \multicolumn{3}{|l|}{ Accountability } \\
\hline Explicit 'rules of the game' & $\sqrt{ }$ & $\sqrt{ }$ \\
\hline Independent report cards & $\mathrm{P}-$ & $\mathrm{P}-$ \\
\hline Full operational accountability & $\mathrm{P}$ & $\mathrm{P}$ \\
\hline Stakeholder involvement in decision making & $\sqrt{ }$ & $\sqrt{ }$ \\
\hline Fishery performance indicators & $\sqrt{ }$ & $\sqrt{ }$ \\
\hline Economic performance indicators & $\mathrm{P}+$ & $\mathrm{P}+$ \\
\hline Ecosystem performance indicators & $\mathrm{P}-$ & $\mathrm{X}$ \\
\hline \multicolumn{3}{|l|}{ Transparency } \\
\hline Non-confidential data easily accessible & $\mathrm{P}$ & $\mathrm{P}$ \\
\hline $\begin{array}{l}\text { Open and publicly recorded decision-making } \\
\text { process }\end{array}$ & $\sqrt{ }$ & $\sqrt{ }$ \\
\hline $\begin{array}{l}\text { Open and systematic process for evaluation and } \\
\text { feedback of past decisions }\end{array}$ & $\mathrm{X}$ & $\mathrm{X}$ \\
\hline \multicolumn{3}{|l|}{ Incentives } \\
\hline $\begin{array}{l}\text { Secure and durable individual or community } \\
\text { harvesting or area fishing rights }\end{array}$ & $\mathrm{P}$ & $\sqrt{ }$ \\
\hline Effective monitoring and enforcement & $\mathrm{P}+$ & $\mathrm{P}+$ \\
\hline $\begin{array}{l}\text { Competitive and well-developed market for fishing } \\
\text { rights }\end{array}$ & $\mathrm{P}$ & $\mathrm{P}+$ \\
\hline Incentives to avoid bycatch and habitat damage & $\mathrm{P}$ & $\mathrm{P}$ \\
\hline \multicolumn{3}{|l|}{ Risk assessment and management } \\
\hline Use of management strategy evaluation & $\mathrm{P}$ & $\mathrm{P}$ \\
\hline Effective use of limit reference points & $\mathrm{P}+$ & $\sqrt{ }$ \\
\hline Effective spatial and harvest management controls & $\sqrt{ }$ & $\mathrm{P}$ \\
\hline Well-defined and agreed to risk boundaries & $\sqrt{ }$ & $\sqrt{ }$ \\
\hline \multicolumn{3}{|l|}{ Adaptability } \\
\hline Adaptive and responsive decision-making & $\mathrm{P}-$ & $\mathrm{P}-$ \\
\hline In-season adjustment to management & $\mathrm{P}$ & $\mathrm{X}$ \\
\hline Nested decision-making structures & $\mathrm{X}$ & $\mathrm{X}$ \\
\hline $\begin{array}{l}\text { Systematic use of localized fisher and community } \\
\text { knowledge }\end{array}$ & $\mathrm{P}$ & $\mathrm{P}$ \\
\hline
\end{tabular}

Notes: $\sqrt{ }=$ governance component fully in place in the fishery; $\mathrm{P}+=$ governance component mostly satisfied, but not yet fully operationalized; $\mathrm{P}=$ governance component partially satisfied, but further development is required; $\mathrm{P}-=$ governance component is not satisfied, but steps towards its development are in place; $\mathrm{X}=$ governance component missing in the fishery.

generating about US\$50 in annual landed value and the SESSF about US\$40 million.

Table 1 shows that although a number of important governance elements already exist in both fisheries, especially in terms of accountability, there are a number of important gaps. Deficiencies exist in both fisheries in terms of transparency, incentives, risk assessment and management, and also adaptability. To some extent the gaps in terms of risk assessment and management, and also adaptability, will be addressed by the full implementation of the HSP, while the issue of incentives will be part of a study on the applicability of the use of ITQs in the NPF to be determined in 2007. In the case of the SESSF, although ITQs have been used since the 1990s, TACs have been set at too high a level to be binding on a number of key species 
[69]. AFMA is the second year of substantial TAC reductions to address this issue. Efforts to address to other gaps identified by the benchmarking are an on-going priority of AFMA.

\section{Concluding remarks}

Many of the world's fisheries are overfished, marine ecosystems are under stress and the net returns from harvesting are well below their potential. The principal cause is poor and ineffective fisheries governance. Although several 'fixes' have been proposed, we contend that only with a logically constructed synthesis that benchmarks performance will fisheries governance achieve its full potential to respond to these challenges.

Building on the insights of the precautionary principle, ecosystem approaches to fisheries management, and risk management, among others, we outline the critical factors required for fisheries governance to deliver ecologically and economically resilient fisheries. These include accountability, authority and responsibility, transparency, incentives, risk assessment and management, and adaptability. Collectively, the five governance factors provide a framework to benchmark and improve fisheries governance. Initial findings from benchmarking in two of Australia's Commonwealth fisheries indicate that the framework provides an important tool to help overcome the underlying cause of unsustainability in capture fisheries - poor and/or ineffective fisheries governance.

\section{References}

[1] Garcia SM. The precautionary principle: its implications in capture fisheries management. Ocean \& Coastal Management 1994;22: 99-125.

[2] Food and Agricultural Organization of the United Nations. Precautionary approach to marine capture fisheries and species introductions. Rome: FAO Technical Guidelines for Responsible Fisheries. No. 2. 1996.

[3] Caddy JF, Mahon R. Reference points for fishery management. Rome: FAO Fisheries Technical Paper. No. 347. 1995.

[4] Brander KM. Cod recruitment is strongly affected by climate when stock biomass is low. ICES Journal of Marine Science 2005;62: 339-43.

[5] González-Laxe F. The precautionary principle in fisheries management. Marine Policy 2005;29:495-505.

[6] Karagiannakos A. Total allowable catch (TAC) and quota management in the European Union. Marine Policy 1996;20:235-48.

[7] Daw T, Gray T. Fisheries science and sustainability in international policy: a study of failure in the European Union's Common Fisheries Policy. Marine Policy 2005;29:189-97.

[8] Maguire J-J. Large demersal fishery in the North Atlantic. In: Swan J, Gréboval D, editors. Report of the international workshop on the implementation of international fisheries instruments and factors of unsustainability and overexploitation in fisheries. Rome: FAO Fisheries Report No. 700. 2004. p. 189-201.

[9] Bax NJ, Tilzey R, Lyle J, Wayte SE, Kloser R, Smith ADM. Providing management advice for deep-sea fisheries: lessons learned from Australia's orange roughy fisheries. In: Shotton R, editor. Deep sea 2003: conference on the governance and management of deep-sea fisheries. Queenstown, New Zealand, 1-5 December 2003. Rome: FAO Fisheries Proceedings No. 3/1, 2005. 718p.
[10] Sainsbury K. Comments on factors of unsustainbility and overexploitation in fisheries. In: Gréboval D, editor. Report and documentation of the international workshop on factors contributing to unsustainability and overexploitation in fisheries. Rome: FAO Fisheries Report No. 672, 2002. p. 167-71.

[11] Rice J. 2003. The British Columbia rockfish trawl fishery. In: Swan J, Gréboval D, editors. Report and documentation of the international workshop of international fisheries instruments and factors of unsustainability and overexploitation in fisheries. Mauritius: 3-7 February, 2003. FAO, Rome, Italy.

[12] Walters CJ, Pearse PH. Stock information requirements for quota management systems in commercial fisheries. Reviews in Fish Biology and Fisheries 1996;6:21-42.

[13] Babcock EA, Pikitch EK, McAllister MK, Apostolaki P, Santora C. A perspective on the use of spatialized indicators for ecosystem-based fishery management through spatial zoning. ICES Journal of Marine Science 2005;62:469-76.

[14] Shin Y-J, Rochet M-J, Jennings S, Field JG, Gislason H. Using sizebased indicators to evaluate the ecosystem effects of fishing. ICES Journal of Marine Science 2005;62:384-96.

[15] Fulton EA, Smith ADM, Punt AE. Which ecological indicators can robustly detect effects of fishing? ICES Journal of Marine Science 2005;62:540-51.

[16] Link JS. Translating ecosystem indicators into decision criteria. ICES Journal of Marine Science 2005;62:569-76.

[17] Hilborn R. The dark side of reference points. Bulletin of Marine Science 2002;70(2):403-8.

[18] Clark WG, Hare SR, Parma AM, Sullivan PJ, Trumble RJ. Decadal changes in growth and recruitment of Pacific halibut (Hippoglossus stenlopsis). Canadian Journal of Fisheries and Aquatic Sciences $1999 ; 56: 242-52$.

[19] Grafton RQ, Kirkley JE, Kompas T, Squires D. Economics for Fisheries Management. Aldershot: Ashgate; 2006.

[20] Jentoft S. Fisheries co-management: delegating government responsibility to fishermen's organizations. Marine Policy 1989;13: 137-51.

[21] Larkin PA. An epitaph for the concept of maximum sustainable yield. Transactions of American Fisheries Society 1977;106:1-11.

[22] Hilborn R. Defining success in fisheries and conflicts in objectives. Marine Policy 2006;31:153-8.

[23] Hilborn R, Orensanz JM, Parma AM. Institutions, incentives and the future of fisheries. Philosophical Transactions of the Royal Society B 2005;360:47-57.

[24] Walters CJ, Martell SJD. Fisheries ecology and management. New Jersey: Princeton University Press; 2004.

[25] Grafton RQ, Arnason R, Bjørndal T, Campbell D, Campbell HF, Clark CW, et al. Incentive-based approaches to sustainable fisheries. Canadian Journal of Fisheries and Aquatic Sciences 2006;63: 699-710.

[26] Healey MC, Hennessey T. The paradox of fairness: the impact of escalating complexity on fisheries management. Marine Policy 1998; 22(2):109-18.

[27] Crowder LB, Osherenko G, Young OR, Airame S, Norse EA, Baron $\mathrm{N}$, et al. Resolving mismatches in US ocean governance. Science 2006;313:617-8.

[28] Pearse PH, Walters CJ. Harvesting regulation under quota management systems for ocean fisheries. Marine Policy 1992;16:167-82.

[29] Organisation for economic Co-operation and Development. Towards sustainable fisheries. Paris: 1997.

[30] Hannesson R. The privatization of the oceans. Cambridge, MA: The MIT Press; 2004.

[31] Pauly D, Christensen V, Guénette S, Pitcher TJ, Sumalia UR, Walters CJ, et al. Towards sustainability in world fisheries. Science 2002;418:689-95.

[32] Garcia SM, Zerbi A, Aliaume C, Do Chi T, Lasserre G. The ecosystem approach to fisheries. Issues, terminology, principles, institutional foundations, implementation and outlook. Rome: FAO Fisheries Technical Paper 2003; No. 443. 
[33] Food and agricultural organization of the United Nations. Rome: Code of Conduct for Responsible Fisheries; 1995.

[34] Garcia SM, Cochrane KL. Ecosystem approach to fisheries: a review of implementation guidelines. ICES Journal of Marine Science 2005;62:311-8.

[35] McEvoy AF. Toward an interactive theory of nature and culture: ecology, production, and cognition in the California fishing industry. In: Worster D, editor. The ends of the earth. Perspectives of modern environmental history. New York: Cambridge University Press; 1988. p. 211-29.

[36] Pinkerton E. Local fisheries co-management: a review on international experiences and their implications for British Columbia salmon management. Canadian Journal of Fisheries and Aquatic Sciences 1994;51:2363-78.

[37] Charles AT. Sustainable fishery systems. Blackwell Science, Osney Mead: Fish and Aquatic Series 5; 2001.

[38] Holling CS. Resilience and stability of ecological systems. Annual Review of Ecology and Systematics 1973;4:1-23.

[39] Pimm Stuart L. The complexity and stability of ecosystems. Nature 1984;307:321-5.

[40] Walters CJ, Hilborn R. Adaptive control of fishing systems. Journal of the Fisheries Research Board of Canada 1976;33:145-59.

[41] Foster E, Howard M, Coffen-Smout S. Implementing integrated oceans management: Australia's south east regional marine plan (SERMP) and Canada's eastern Scotian shelf integrated management (ESSIM) initiative. Marine Policy 2005;29:391-405.

[42] World Bank. Saving fish and fishers. Toward sustainable and equitable governance of the global fishing sector. Washington, DC: Report 29090-GLB; 2004.

[43] Utne IB. Systems engineering principles in fisheries management. Marine Policy 2006;30:624-34.

[44] Lane DE, Stephenson RL. Institutional arrangements for fisheries: alternate structures and impediments to change. Marine Policy 2000;24:385-93.

[45] Sen S, Nielsen JP. Fisheries co-management: a comparative analysis. Marine Policy 1996;20:405-18.

[46] Lane DE, Stephenson RL. A framework for risk analysis in fisheries decision-making. ICES Journal of Marine Science 1998;55:1-13.

[47] Campbell D, Stokes A, Brown D. Issues in monitoring fisheries management performance. ABARE Conference Paper 96.20 presented at the VIII International Fisheries Economics and Trade Conference. Marrakesh, Morocco: 1-4 July 1996.

[48] Devlin RA, Grafton RQ. Economic rights and environmental wrongs: property rights for the common good. Cheltenham: Edward Elgar; 1998.

[49] Grafton RQ. Governance of the commons: a role for the state? Land Economics 2000;76(4):504-17.

[50] Kompas T, Che TN, Grafton RQ. Technical efficiency effects of input controls: evidence from Australia's banana prawn fishery. Applied Economics 2004;36:1631-41.

[51] Hedley C. The 1998 agreement on the International Dolphin Conservation Program: recent developments in the Tuna-Dolphin Controversy in the Eastern Pacific Ocean. Ocean Development \& Intlernational Law 2001;32:71-92.

[52] Holland D, Schnier KE. Individual habitat quotas for fisheries. Journal of Environmental Economics 2006;51(1):72-92.
[53] Ludwig D, Hilborn R, Walters C. Uncertainty, resource exploitation, and conservation: lessons from history. Science 260 (1993) 7,36 .

[54] Wilson J, Kleban P, McKay S, Townsend R. Management of multispecies fisheries and chaotic population dynamics. ICES Marine Science Symposium 1991;193:287-300.

[55] Grafton RQ, Silva-Echenique J. How to manage nature? Strategies, predator-prey models, and chaos. Marine Resource Economics 1997;12:127-43.

[56] Grafton RQ, Kompas T, Lindenmayer D. Marine reserves with ecological uncertainty. Bulletin of Mathematical Biology 2005;67: 957-71.

[57] Sainsbury KJ, Punt AE, Smith ADM. Design of operational management strategies for achieving fishery ecosystem objectives. ICES Journal of Marine Science 2000;57:731-41.

[58] McDonald AD, Little LR, Gray R, Fulton E, Sainsbury KJ, Lyne VD. Multiple-use Management Strategy Evaluation for Coastal Marine Ecosystems using In Vitro. In: Zerger A, Argent RM, editors. MODSIM 2005 international congress on modelling and simulation. modelling and simulation society of Australia and New Zealand, December 2005. p. 170-6. ISBN:0-9758400-2-9. 〈http://www.mssanz.org.au/modsim05/papers/mcdonald.pdf $>$.

[59] Hilborn R, Walters CJ. Quantitative fisheries stock assessment: choice, dynamics and uncertainty. New York: Chapman \& Hall; 1992.

[60] Dietz T, Ostrom E, Stern PC. The struggle to govern the commons. Science 2003;302(2 December):1907-12.

[61] Jentoft S. The community: a missing link of fisheries management. Marine Policy 2000;24:53-9.

[62] Berkes F, Colding J, Folke C. Traditional ecological knowledge. Ecological Applications 2000;10(5):1251-62.

[63] Grafton RQ. Social capital and fisheries governance. Ocean \& Coastal Management 2005;48:753-66.

[64] McLoughlin R, Findlay V. Implementation of effective fisheries management. In Outlook '05, Canberra, Australia, 2 March 2005. $\langle$ http://www.abare.gov.au/outlook/program/dat.html $\rangle$.

[65] Hilborn R, Annala J, Holland DS. The cost of overfishing and management strategies for new fisheries on slow-growing fish: orange roughy (Hoplostethus atlanticus) in New Zealand. Canadian Journal of Fisheries and Aquatic Sciences 2006;63.

[66] Kompas T, Grafton RQ, Che N, Gooday P. Development of methods and information to support the assessment of economic performance in Commonwealth fisheries, Australian Bureau of Agricultural and Resource Economics, Report to the Fisheries Research and Development Corporation, Canberra; 2007.

[67] Marine Stewardship Council. Marine Stewardship Council Guidance to potential or actual clients: The MSC Fishery Assessment \& Certification Process; 2005. Available at 〈http://www.msc.org/assets/ docs/fishery_certification/Guidance_to_Clients_V1.pdf $\rangle$.

[68] Fox KJ, Grafton RQ, Kompas T, Che TN. Productivity and capacity reduction: the case of a fishery. Australian Journal of Agricultural and Resource Economics 2006;50:189-206.

[69] Kompas T, Gooday P. The failure of 'command and control' approaches to fisheries management: lessons from Australia. International Journal of Global Environmental Issues, in press. 